УДК 616.125-008.313.2/.3+615.273

DOI: 10.26435/UC.V0I3(32).338

\author{
А.Э. Багрий ${ }^{1}$, О.А. Приколота ${ }^{1}$, Е.Е. Ковыршина ${ }^{2}$, К.А. Котова ${ }^{3}$, Н.О. Реутова ${ }^{1}$ \\ ${ }^{1} Г 00$ ВПО «Донецкий национальный медицинский университет имени М. Горького», Донецк \\ ${ }^{2}$ Донецкое клиническое территориальное медицинское объединение, Донецк \\ ${ }^{3}$ Дорожная клиническая больница станции Донецк, Донецк
}

\title{
АНТИТРОМБОТИЧЕСКАЯ ТЕРАПИЯ ПРИ ВПЕРВЫЕ ВЫЯВЛЕННОЙ ФИБРИЛЛЯЦИИ ПРЕДСЕРДИЙ
}

Фибрилляция предсердий (ФП) является наиболее распространенной аритмией. По прогнозам, в мире к 2050 году число взрослых, страдающих ФП, достигнет 8 миллионов [1]. Увеличение распространенности ФП связано со старением населения, ростом продолжительности жизни больных с сердечно-сосудистыми заболеваниями, усилением выявления асимптомных форм ФП [2]. С практической точки зрения многие эксперты считают целесообразным выделение впервые выявленной ФП (ВВФП), рассмотрению тактики ведения пациентов при этом варианте аритмии посвящены отдельные Рекомендации (последние - в 2017г. American Academy of Family Physicians - AAFP) [3]. ФП связана с высоким риском развития тромбоэмболических осложнений (ТЭО) независимо от варианта (ВВФП или ранее диагностированная ФП) [4]. Лица, имеющие ФП, демонстрируют пятикратное повышение риска развития ишемических (эмболических) инсультов, в сравнении со здоровыми лицами [5]. В этой связи, одним из приоритетных компонентов врачебной тактики при ФП в целом, а также при ВВФП, в частности, является применение антитромботических препаратов (АТП) для уменьшения риска ТЭО. Антитромботическая терапия при ВВФП проводится с использованием тех же принципов и лечебных подходов, что и при других вариантах ФП.

Целью настоящего сообщения явилось обсуждение современных подходов к назначению АТП у лиц с ВВФП так как, по мнению ряда авторитетных специалистов [5-7], у такой категории больных часто имеет место достаточно длительная задержка с началом применения АТП, поэтому весьма важно привлечь внимание практикующего врача к необходимости безотлагательного начала полноценной антитромботической терапии при ВВФП [8].

Важнейшим элементом выбора тактики применения АТП является оценка риска развития
TЭО (шкала CHA2DS2-VASC) [9] и риска кровотечений (шкала HAS-BLED) [10] (табл. 1., табл. 2.).

Согласно рекомендациям экспертов AAFP, претендентами на терапию пероральными антикоагулянтами (ПОАК) являются пациенты с ВВФП при наличии суммы баллов $\geqslant 2$ по шкале CHA2DS2-VASC. В случаях, если количество баллов по этой шкале равно 1, назначение ПОАК или аспирина рекомендуют рассматривать с учетом риска кровотечений и предпочтений больного. При этом отсутствие клинических факторов риска ТЭО - основание для отказа от АТП.

При оценке риска кровотечений, его считают высоким при наличии $\geqslant 3$ баллов по шкале HASBLED. Высокий риск развития геморрагических осложнений не является критерием для отказа от АТП, а сигнализирует о необходимости более тщательного наблюдения, коррекции потенциально изменяемых факторов риска кровотечений, снижения дозы новых ПОАК (НПОАК).

В современной практике ВВФП в качестве эффективной терапии, направленной на предотвращение ТЭО, рекомендованы следующие группы ПОАК: антагонисты витамина К (АВК) и НПОАК, не являющиеся антагонистами витамина К [11]. Первые используются в качестве эффективных АТП при ФП уже более 60 лет, они снижают частоту возникновения ишемических инсультов примерно на 60\% [12]. К АВК относятся аценокумарол, фениндион и, наиболее часто используемый, варфарин. Механизм действия ABK [13] заключается в блокировании фермента (витамин-К-редуктазы) с последующим нарушением $\gamma$-карбоксилирования остатков глутамата на N-концевых участках витамин К-зависимых факторов коагуляции: II, VII, IX, X. Это приводит к выработке в печени частично карбокси-

(c) А.Э. Багрий, О.А. Приколота, Е.Е. Ковыршина, К.А. Котова, Н.О. Реутова, 2019 (c) Университетская Клиника, 2019 
Таблица 1. Клиническая шкала CHA2DS2-VASC для оценки риска инсульта и системных эмболий у пациентов с ФП

\begin{tabular}{lc}
\hline \multicolumn{1}{c}{ Факторы риска } & Баллы \\
\hline $\begin{array}{l}\text { Хроническая сердечная недостаточность - наличие ее симптомов или объективные } \\
\text { доказательства снижения фракции выброса левого желудочка }\end{array}$ & +1 \\
\hline $\begin{array}{l}\text { Артериальная гипертензия - уровень артериального давления в состоянии } \\
\text { покоя > 140/90 мм рт.ст. при двух повторных измерениях или лечение } \\
\text { антигипертензивными препаратами }\end{array}$ & +1 \\
\hline Возраст 75 лет & +2 \\
\hline $\begin{array}{l}\text { Сахарный диабет - гликемия натощак > } 7 \text { ммоль/л или текущая терапия } \\
\text { сахароснижающими препаратами и/или инсулином }\end{array}$ & +1 \\
\hline Перенесенный инсульт, транзиторная ишемическая атака, тэо & +2 \\
\hline $\begin{array}{l}\text { Наличие сосудистых заболеваний - инфаркт миокарда в анамнезе, заболевание } \\
\text { периферических артерий или атеросклеротическая бляшка в аорте }\end{array}$ & +1 \\
\hline Возраст 65-74 года & +1 \\
\hline Женский пол & +1 \\
\hline
\end{tabular}

Клиническая шкала HAS-BLED для оценки риска развития кровотечений у пациентов с ФП

\begin{tabular}{lc}
\hline \multicolumn{1}{c}{ Фактор риска } & Баллы \\
\hline $\begin{array}{l}\text { Артериальная гипертензия, особенно повышение систолического } \\
\text { артериального давления >160 мм рт.ст. }\end{array}$ & +1 \\
\hline $\begin{array}{l}\text { Нарушение функции почек } \\
\text { Нарушение функции печени }\end{array}$ & +1 \\
\hline Перенесенный инсульт & +1 \\
\hline Кровотечение в анамнезе или предрасположенность к его развитию & +1 \\
\hline $\begin{array}{l}\text { Лабильное МНО или период времени в терапевтическом диапазоне <60\% у пациентов, } \\
\text { которые принимают антагонисты витамина К }\end{array}$ & +1 \\
\hline Возраст >65 лет & +1 \\
\hline $\begin{array}{l}\text { Использование лекарственных препаратов, предрасполагающих к развитию кровотечения, } \\
\text { такие как АТП и нестероидные противовоспалительные препараты }\end{array}$ & +1 \\
\hline Чрезмерное употребление алкоголя $\geqslant 8$ доз/неделю & + \\
\hline
\end{tabular}

лированных и декарбоксилированных факторов свертывания со сниженной коагулянтной активностью. Кроме того, препараты ингибируют карбоксилирование регуляторных антикоагулянтных протеинов C, S и Z и тем самым обладают прокоагулянтной активностью, хотя антикоагулянтный эффект является доминирующим. Среди АВК наиболее изучен варфарин: по данным Всемирной Организации Здравоохранения, 2005 г., он - «один из наиболее эффективных и безопасных препаратов в здравоохранении». Альтернативные варианты АВК, включающие аценокумарол (Синкумар) и фениндион (Фенилин), терапевтический эффект которых развивается при достижении целевого уровня протромбинового индекса в пределах 40-60\%, сейчас используются гораздо реже варфарина. Именно варфарин рассматривается в качестве препарата выбора во всех современных рекомендациях по ФП. Применение варфарина требует соблюдения ряда обязательных условий:

1) прием утром строго натощак;

2) необходимость контроля международного нормализованного отношения - МНО (обычно на 2-3 день от начала приема, затем 2 раза в неделю, затем 1 раз в неделю, в последующем не реже 1 раза в месяц; целевые уровни МНO на фоне приема варфарина - 2,0-3,0);

3) необходимость учета возможных взаимодействий варфарина с другими препаратами и 
пищевыми продуктами;

4) информированность больного и постоянный контроль приверженности к лечению;

5) отсутствие назначения нагрузочных доз (обычная стартовая и начальная поддерживающая дозы - 5 мг/сут, а у пожилых - 2,5 мг/сут).

Для достижения целевого уровня МНО от начала приема варфарина обычно требуется 60-72 часа, при необходимости более быстрого начала гипокоагуляции предусматривают его сочетанное использование с парентеральными антикоагулянтами на 5-7 дней.

Следует отметить выгодные характеристики АBК [12]. Они не выводятся почками, поэтому могут применяться больными с тяжелой почечной недостаточностью. Для пациентов привлекательна выгодная стоимость препаратов. Необходимость периодического мониторинга MHO способствует регулярному контакту врача с пациентом, в тоже время это может составлять неудобства и дополнительные расходы, что приводит к снижению приверженности к лечению. Отрицательной стороной АВК является их довольно узкое терапевтическое окно, что требует регулярного контроля состояния системы коагуляции и коррекции дозы препаратов. На начальном этапе терапии АВК обладают протромботическими свойствами, поскольку ингибируют антикоагулянтные протеины C и S быстрее, чем факторы свертывания, а это создает временный дисбаланс в пользу прокоагуляции. Нельзя не упомянуть о множестве лекарственных и пищевых взаимодействий, присущих данной группе. При передозировке купирование эффекта АВК осуществляется витамином К2 и его аналогами, однако возможность их использования в отечественной клинической практике ограничена.

В качестве альтернативы ABК (в первую очередь варфарину) используют НПОАК, представленные следующими основными классами: 1) прямой ингибитор тромбина (дабигатран), 2) ингибиторы фактора Ха (апиксабан, ривароксабан, эдоксабан) [14]. Их позиция в профилактике ТЭО при ФП обосновывается данными целого ряда крупнейших исследований (табл. 3.). Фармакологические характеристики НПОАК обеспечивают практические преимущества перед терапией АВК [15]. Прямое воздействие на фактор Ха или тромбин обеспечивает более быстрый антикоагулянтный эффект - в течение 1-4 ч по сравнению с косвенным механизмом действия через множественные факторы свертывания (для варфарина). Препараты этой группы имеют более предсказуемые фармакокинетику и фармакодинамику и более низкий потенциал для пищевого и лекарственного взаимодействия, и, таким образом, могут назначаться в фиксирован- ных дозах без необходимости диетических ограничений и рутинного контроля параметров коагуляции. Риск геморрагического инсульта и внутричерепных геморрагий при их использовании ниже в сравнении с АВК. Несмотря на это, существуют и негативные моменты: так, пока малодоступны специфические нейтрализующие препараты для НПОАК, которые можно было бы применить при возникновении кровотечения на фоне их приема. Препараты этой группы элиминируются почками, в связи с чем их не рекомендуют принимать пациентам со сниженным клиренсом креатинина. Стоимость НПОАК достаточно высока, тем не менее, длительная терапия с их использованием может быть экономически более рентабельной в основном из-за меньших затрат на мониторинг МНО и сокращения числа пациентов с ТЭО.

Охарактеризуем два относительно более распространенных в отечественной клинической практике НПОАК. Ривароксабан - представитель группы прямых ингибиторов Ха фактора (изучен при ФП в исследовании ROCKET-AF) [16]. Его эффект опосредован снижением продукции тромбина и угнетением образования фибрина. Использование ривароксабана имеет следующие особенности:

1) прием 1 раз в сутки, строго во время еды;

2) наличие фиксированных дозировок при ФП: при скорости клубочковой фильтрации (СКФ) > 50 мл/мин - по 20 мг/сутки, 30-49 мл/ мин - по 15 мг/сутки, < 30 мл/мин - применение не рекомендуется;

3) пропуск приема может увеличить риск развития ишемического инсульта, в связи с чем пациенту нужно избегать таких ситуаций и следует иметь запас ривароксабана.

Дабигатран относится к прямым ингибиторам тромбина (изучен при ФП в многоцентровом рандомизированном исследовании RE-LY) [17]. Угнетение препаратом активности тромбина приводит к нарушению образования полимеров фибрина. Из условий применения дабигатрана следует подчеркнуть:

1) наличие фиксированных дозировок: при СКФ >30 мл/мин - по 150 мг 2 раза в сутки, при 15-30 мл/мин - по 75 мг 2 раза в сутки, <15 мл/ мин - не применять;

2) двукратный прием в сутки требует высокой приверженности больного к лечению;

3) пропуск приема может увеличить риск развития ишемического инсульта, в связи с чем нужно соблюдать те же предосторожности, что и для ривароксабана;

4) взаимодействует с верапамилом, ввиду чего эта комбинация не рекомендуется.

Несмотря на введение в клиническую прак- 
Сравнительная характеристика НПОАК, одобренных к клиническому применению [11]

\begin{tabular}{|c|c|c|c|c|}
\hline & $\begin{array}{c}\text { Дабигатран } \\
\text { (PКИ - RE-LY) } \\
\end{array}$ & $\begin{array}{c}\text { Ривароксабан } \\
\text { (РКИ - ROCK- } \\
\text { ET-AF) } \\
\end{array}$ & $\begin{array}{c}\text { Апиксабан } \\
\text { (PKИ - AR- } \\
\text { ISTOTLE) } \\
\end{array}$ & $\begin{array}{c}\text { Эдоксабан } \\
\text { (PКИ - ENGAGE } \\
\text { AF-TIMI 48) } \\
\end{array}$ \\
\hline Механизм действия & $\begin{array}{c}\text { Прямой ингиби- } \\
\text { тор тромбина }\end{array}$ & \multicolumn{3}{|c|}{ Прямые ингибиторы Ха фактора свертывания } \\
\hline Биодоступность, \% & 6 & $\begin{array}{l}66 \text { натощак, 80- } \\
100 \text { с пищей }\end{array}$ & 50 & 62 \\
\hline $\begin{array}{l}\text { Время пиковой } \\
\text { концентрации, ч }\end{array}$ & 3 & $2-4$ & 3 & $1-2$ \\
\hline $\begin{array}{l}\text { Период полу- } \\
\text { выведения, ч }\end{array}$ & $12-17$ & $5-13$ & $9-14$ & $10-14$ \\
\hline Выведение & 80\% почки & $\begin{array}{l}\text { 66\% печень, } \\
\text { 33\% почки }\end{array}$ & 27\% почки & 50\% почки \\
\hline Доза при ФП & $\begin{array}{l}150 \text { мг } 2 \text { p/день; } \\
110 \text { мг } 2 \text { р/день }\end{array}$ & 20 мг 1 раз/день & 5 мг 2 раза/день & $\begin{array}{l}60 \text { мг } 1 \text { р/день; } \\
30 \text { мг } 1 \text { р/день }\end{array}$ \\
\hline $\begin{array}{l}\text { Снижение дозы } \\
\text { у определенных } \\
\text { категорий пациентов }\end{array}$ & $\begin{array}{c}110 \text { мг } 2 \text { р/день } \\
\text { для лиц с клирен- } \\
\text { сом креатини- } \\
\text { на 30-49 мл/мин }\end{array}$ & $\begin{array}{c}15 \text { мг } 1 \text { р/день, } \\
\text { если клиренс } \\
\text { креатинина } \\
\text { 30-49 мл/мин }\end{array}$ & $\begin{array}{c}2,5 \text { мг } 2 \text { р/день, } \\
\text { если } \geqslant 2 \text { из: воз- } \\
\text { раст } \geqslant 80 \text { лет, } \\
\text { масса } \leqslant 60 \text { кг, } \\
\text { креатинин кро- } \\
\text { ви } \geqslant 133 \text { мкмоль } / л\end{array}$ & $\begin{array}{c}\text { Вместо } 60-30 \text {, а } \\
\text { вместо } 30-15 \text { мг/ } \\
\text { день, если: кли- } \\
\text { ренс креатинина } \\
30-49 \text { мл/мин, } \\
\text { масса } \leqslant 60 \text { кг }\end{array}$ \\
\hline \multicolumn{5}{|c|}{ Протокол крупнейших РКИ при ФП: } \\
\hline Количество лиц & 18113 & 14264 & 18201 & 21105 \\
\hline Длительность, лет & 2 & 1,9 & 1,8 & 2,8 \\
\hline $\begin{array}{l}\text { Рандомизированные } \\
\text { группы }\end{array}$ & $\begin{array}{l}\text { Варфарин *; да- } \\
\text { бигатран -150 } \\
\text { мг } 2 \text { р/день; и } \\
110 \text { мг } 2 \text { р/ день } \\
\end{array}$ & $\begin{array}{l}\text { Варфарин *; ри- } \\
\text { вароксабан } 20 \\
\text { мг } 1 \text { р/день }\end{array}$ & $\begin{array}{l}\text { Варфарин *; апик- } \\
\text { сабан } 5 \text { мг } 2 \text { р/день }\end{array}$ & $\begin{array}{c}\text { Варфарин *; эдок- } \\
\text { сабан - 60 мг } \\
1 \text { р/день; и } 30 \\
\text { мг } 1 \text { р/день }\end{array}$ \\
\hline Средний возраст, г & 71,5 & 73 & 70 & 72 \\
\hline Мужской пол, \% & 63,6 & 60,3 & 64,5 & 61,9 \\
\hline
\end{tabular}

По данным этих РКИ: НПОАК в сравнении с варфарином:

\begin{tabular}{|c|c|c|c|c|}
\hline \multirow{2}{*}{$\begin{array}{l}\text { Ишемические } \\
\text { инсульты + ТЭО }\end{array}$} & $\begin{array}{l}\text { На 35\% меньше, } \\
\text { р<0,001 (150 мг) }\end{array}$ & \multirow{2}{*}{$\begin{array}{l}\text { На 12\% мень- } \\
\text { ше, p<0,001 }\end{array}$} & \multirow{2}{*}{$\begin{array}{l}\text { На 21\% мень- } \\
\text { ше, } p<0,001\end{array}$} & $\begin{array}{c}\text { На 13\% меньше, } \\
\text { р<0,001 (60 мг) }\end{array}$ \\
\hline & $\begin{array}{l}\text { На 11\% меньше, } \\
\text { p<0,001 (110 мг) }\end{array}$ & & & $\begin{array}{l}\text { На } 13 \% \text { больше, } \\
\text { p=0,005 (30 мг) }\end{array}$ \\
\hline \multirow{2}{*}{ Большие кровотечения } & $\begin{array}{l}\text { Нет отличий } \\
(150 \mathrm{Mr})\end{array}$ & \multirow{2}{*}{ Нет отличий } & \multirow{2}{*}{$\begin{array}{l}\text { На 31\% мень- } \\
\text { ше, p<0,001 }\end{array}$} & $\begin{array}{l}\text { На 20\% меньше, } \\
\text { p<0,001 (60 мг) }\end{array}$ \\
\hline & $\begin{array}{l}\text { На 20\% меньше, } \\
\text { p=0,003 (110 мг) }\end{array}$ & & & $\begin{array}{l}\text { На 53\% меньше, } \\
\text { p<0,001 (30 мг) }\end{array}$ \\
\hline \multirow{2}{*}{$\begin{array}{l}\text { Интракраниальные } \\
\text { кровотечения }\end{array}$} & $\begin{array}{l}\text { На 58\% меньше, } \\
\text { p<0,001 (150 мг) }\end{array}$ & \multirow{2}{*}{$\begin{array}{l}\text { На 33\% мень- } \\
\text { ше, } p=0,02\end{array}$} & \multirow{2}{*}{$\begin{array}{l}\text { На 58\% мень- } \\
\text { ше, p<0,001 }\end{array}$} & $\begin{array}{l}\text { На 53\% меньше, } \\
\text { p<0,001 (60 мг) }\end{array}$ \\
\hline & $\begin{array}{l}\text { На 71\% меньше, } \\
\text { p<0,001 (110 мг) }\end{array}$ & & & $\begin{array}{l}\text { На 70\% меньше, } \\
\text { p<0,001 (30 мг) }\end{array}$ \\
\hline
\end{tabular}

Примечание. РКИ - рандомизированное контролируемое исследование; * - под контролем МНО.

тику новых АТП, данные современных исследований демонстрируют, что значительная доля пациентов остается без терапии, направленной на профилактику ТЭО. По результатам исследования Willey V. et.al. [5], среди пациентов с неклапанной ВВФП, которым было рекомендовано лечение согласно количеству баллов $\geqslant 2$ по шкале риска ТЭО, более половины (58\%) не получали лечение ПОАК. При этом, наиболее часто назначаемым препаратом был варфарин, хотя введение НПОАК во врачебную практику пред- шествовало началу исследования. Более оптимистичные данные демонстрируют Bassand J.P. et.al. [18]: на момент постановки диагноза ВВФП 60,8\% пациентов были назначены ПОАК, причем 50\% получали АВК, а 10,8\% - НПОАК. Доля пациентов, получающих АТП, увеличивалась с ростом оценки по шкале CHA2DS2-VASC, будучи самой низкой для пациентов с показателем 0 (41,6\%) и наибольшей при количестве баллов 5 (67,5\%). Использование ПОАК снижалось с возрастанием оценки по шкале HAS-BLED с 76,5\% до 49,8\% 
для пациентов с 0 и $\geqslant 4$ баллов соответственно. Данные, полученные из международного региcтра GARFIELD-AF [8] за пятилетний период времени, свидетельствуют об увеличении назначения АТП при ВВФП в основном за счет применения НПОАК, а также о снижении применения $\mathrm{ABK}$ и антиагрегантов в качестве монотерапии и в комбинации. Авторы отметили, что НПОАК чаще $\mathrm{ABK}$ использовались пожилыми, а также лицами, принимающими нестероидные противовоспалительные препараты. Пациентам с артериальной гипертензией, ишемической болезнью сердца, сахарным диабетом и хронической болезнью почек чаще назначали $\mathrm{ABK}$, в ряде случаев в сочетании с антиагрегантами.

Таким образом, в целях снижения избыточного риска ТЭО при каждом случае выявления ФП требуется оценка такого риска и применение оптимальной антитромботической терапии. Для корректного назначения ПОАК (АВК или НПОАК) необходимо ориентироваться на современные рекомендации. Несмотря на рост использования АТП при ВВФП, остается значительной доля пациентов, которые не получают ПОАК.

А.Э. Багрий' , О.А. При-

колота ${ }^{1}$, Е.Е. Ковыриина ${ }^{2}$, К.А. Котова ${ }^{3}$, Н.О. Реутова ${ }^{1}$

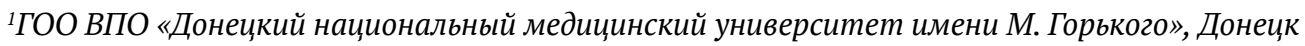
${ }^{2}$ Донецкое клиническое территориальное медицинское объединение, Донецк

${ }^{3}$ Дорожная клиническая больница станции Донецк, Донецк

\section{АНТИТРОМБОТИЧЕСКАЯ ТЕРАПИЯ ПРИ ВПЕРВЫЕ ВЫЯВЛЕННОЙ ФИБРИЛЛЯЦИИ ПРЕДСЕРДИЙ}

Статья посвящена вопросу современной тактики назначения антитромботических препаратов у лиц с впервые выявленной фибрилляцией предсердий одним из вариантов наиболее распространенного нарушения ритма, связанного с высоким риском развития тромбоэмболических осложнений. Важной задачей является привлечение внимания специалистов к необходимости безотлагательного начала тромбопрофилактики. Рассмотрены ведущие подходы к выбору антитромботической терапии на основании клини- ческих шкал CHA2DS2-VASC и HAS-BLED, обсуждены выгодные и отрицательные характеристики антагонистов витамина К и новых пероральных антикоагулянтов, а также особенности условий использования отдельных представителей препаратов этих групп.

Ключевые слова: впервые выявленная фибрилляция предсердий, антитромботическая терапия, пероральные антикоагулянты, тромбоэмболические осложнения.

\section{A.E. Bagry ${ }^{1}$, O.A. Prikolota ${ }^{1}$, E.E. Kovyrshina ${ }^{2}$, K.A. Kotova ${ }^{3}$, N.O. Reutova ${ }^{1}$ \\ ${ }^{1}$ SEI HPE «M. Gorky Donetsk National Medical University», Donetsk \\ ${ }^{2}$ Donetsk clinical territorial medical association, Donetsk \\ ${ }^{3}$ Road clinical hospital of Donetsk station, Donetsk}

\section{ANTITHROMBOTIC TREATMENTS IN CASE OF NEWLY DIAGNOSED ATRIAL FIBRILLATION}

The aim of the article is to attract attention of medical practitioners to the problem of under-use and late beginning of antithrombotic medications in patients with newly diagnosed atrial fibrillation. Thromboprophylaxis in these patients should be started as soon as possible, and the main principles of antithrombotic treatments are the same as in atrial fibrillation in general. The choice of antithrombotics is based on the CHA2DS2-VASC and
HAS-BLED clinical scales, as well as on clinical features and patients' preferences. The main positive and negative characteristics of vitamin $\mathrm{K}$ antagonists and new oral anticoagulants were also discussed.

Key words: newly diagnosed atrial fibrillation, antithrombotic treatments, oral anticoagulants, thromboembolic disorders. 


\section{ЛИТЕРАТУРА / REFERENCES}

1. Palamaner S. S. G., Bhave P., Girotra S. et al. Sex-specific comparative effectiveness of oral anticoagulants in elderly patients with newly diagnosed atrial fibrillation. Circulation: Cardiovascular Quality and Outcomes. 2017; 10: e003418. doi: 10.1161/CIRCOUTCOMES.116.003418

2. Williams B., Evans M., Honushefsky A., Berger P. Clinical prediction model for time in therapeutic range while on warfarin in newly diagnosed atrial fibrillation. I Am Coll Cardiol. 2017; 69 (11): 549. doi: 10.1161/JAHA.117.006669

3. Frost J., Campos-Outcalt D., Hoelting D. et al. Atrial fibrillation guideline summary. The Annals of Family Medicine. 2017;15(5):490-491. doi: 10.1370/afm.2146.

4. Galvão Braga C., Ramos V., Vieira C. et al. New-onset atrial fibrillation during acute coronary syndromes: Predictors and prognosis. Revista Portuguesa de Cardiologia. 2014; 33 (5): 281-287. doi: 10.1016/j.repc.2013.10.017

5. Willey V., Franchino-Elder J., Fu A. et al. Treatment and persistence with oral anticoagulants among newly diagnosed patients with non-valvular atrial fibrillation: a retrospective observational study in a US commercially insured and Medicare Advantage population. BMJ Open. 2018; 8 (6): e020676. doi: 10.1136/bmiopen-2017-020676

6. Khurshid S., Weng L., Hulme O., Ellinor P., Lubitz S. Factors associated with anticoagulation delay following newonset atrial fibrillation. Am J Cardiol. 2017; 120 (8): 13161321. doi: 10.1016/j.amjcard.2017.07.017

7. Haim M., Hoshen M., Reges O. et al. Prospective National Study of the prevalence, incidence, management and outcome of a large contemporary cohort of patients with incident non-tvalvular atrial fibrillation. J Am Heart Assoc. 2015; 4: e001486. doi: 10.1161/JAHA.114.001486

8. Camm A., Accetta G., Ambrosio G. et al. Evolving antithrombotic treatment patterns for patients with newly diagnosed atrial fibrillation. Heart. 2016; 103 (4): 307-314. doi: 10.1136/heartjnl-2016-309832

9. Lip G., Nieuwlaat R., Pisters R., Lane D., Crijns H. Refining clinical risk stratification for predicting stroke and thromboembolism in atrial fibrillation using a novel risk factor-based approach. Chest. 2010; 137 (2): 263-272. doi: 10.1378/chest.09-1584

10. Pisters R., Lane D., Nieuwlaat R. et al. A novel user-friendly score (HAS-BLED) to assess 1 -year risk of major bleeding in patients with atrial fibrillation. Chest. 2010;138 (5): 1093-1100. doi: 10.1378/chest.10-0134

11. Kirchhof P., Benussi S., Kotecha D. et al. 2016 ESC Guidelines for the management of atrial fibrillation developed in collaboration with EACTS. Eur Heart J. 2016; 37 (38): 28932962. doi: 10.1093/ejcts/ezw313

12. Zirlik A., Bode C.Vitamin K antagonists: relative strengths and weaknesses vs direct oral anticoagulants for stroke prevention in patients with atrial fibrillation. J Thromb Thrombolysis. 2016; 43 (3): 365-379. doi: 10.1007/s11239016-1446-0

13. Ageno W., Gallus A., Wittkowsky A. et al. Oral anticoagulant therapy. Chest. 2012; 141 (2): e44S-e88S. doi: 10.1378/ chest.11-2292

14. Voukalis C., Lip G., Shantsila E. Emerging tools for stroke prevention in atrial fibrillation. EBioMedicine. 2016; 4: 2639. doi: 10.1016/j.ebiom.2016.01.017

15. Heidbuchel H., Verhamme P., Alings M. et al. Updated European Heart Rhythm Association Practical Guide on the use of non-vitamin $\mathrm{K}$ antagonist anticoagulants in patients with non-valvular atrial fibrillation. Europace. 2015; 17 (10): 1467-1507. doi: 10.1093/europace/euv309

16. Patel M., Mahaffey K., Garg J. et al. Rivaroxaban versus warfarin in nonvalvular atrial fibrillation. New England Journal of Medicine. 2011; 365 (10): 883-891. doi: 10.1056/ NEJMoa1009638

17. Connolly S., Ezekowitz M., Yusuf S. et al. Dabigatran versus warfarin in patients with atrial fibrillation. New England Journal of Medicine. 2009; 361 (12): 1139-1151. doi: 10.1056/NEJMoa0905561

18. Bassand I., Accetta G., Camm A. et al. Two-year outcomes of patients with newly diagnosed atrial fibrillation: results from GARFIELD-AF. Eur Heart J. 2016; 37 (38): 2882-2889. doi: 10.1093/eurheartj/ehw233 